\title{
NOTAS SOBRE RELACIONES INTERCONFESIONALES EN LA ARGELIA COLONIAL: LA ISLAMIZACIÓN DE UN JOVEN MALAGUEÑO EN MOSTAGANEM EN 1854
}

Por

JUAN BTA. VILAR

Y

ANA M. a SÁNCHEZ DÍAZ

\section{Nota preliminar}

En el Archivo del Ministerio de Asuntos Exteriores, Sección Correspondencia Consular (Argel), leg. 1.818, se conserva un expediente referido a la asimilación religiosa - y consiguiente transculturización- de cierto español por los musulmanes en la Argelia francesa.

Del suceso, fechado en Mostaganem en 1854, dimos somera noticia en otro lugar en base a la documentación de referencia (1). Ahora publicamos la fuente precedida de breve glosa.

Desde luego no era éste el primer caso de abjuración del cristianismo entre españoles registrado en Argelia. Antes al contrario, fueron frecuentes en la fase pre-colonial (2), e incluso en los primeros tiempos de la colonia (3), etapa en que, aquí como en Marruecos, presidiarios y desertores no dudaban en cambiar - siquiera aparentemente - su fe religiosa para escapar a la extradición.

(1) JUAN BTA. VILAR, Emigración española a Argelia (1830-1900). Colonización hispánica de la Argelia francesa. C. S. I. C. Madrid. 1975, p. 390.

(2) J. B. VILAR, aLa sociedad española en la Argelia otomana (1791-1814)", Almenara, 9 (Madrid, 1976), ps. 63-72; VILAR, "Relaciones comerciales hispano-argelinas en el período 1791-1814", Hispania, t. XXXIV (Madrid, 19741, ps. 435-442; VILAR, «Relaciones diplomáticas y comerciales hispano-argelinas en las postrimerías de la Argelia otomana (1814-1830)", Hispania, XXXV| (1976), ps, 623-638; VILAR, "Menorca y el rescate de cautivos españoles en Argel por la misión Ortiz de Zugasti en 1827", Revista de Menorca, t. LXXII (Mahón, 1985), ps. 333-363; MiKEL DE EPALZA, «Los Soler menorquines en el Mediterráneo islámico (Magrebi-Oriente) y la expansión magrebí de los menorquines. Sigjos XVIIIX|Xn, Revista de Menorca, LXX| (1980), ps. 106-112.

(3) VILAR, Emigración...., Op. cit. ps. 390-392. 
El caso que nos ocupa tampoco sería el último. Por más que las relaciones de españoles y argelinos no siempre resultaron fáciles, no cabe duda de que fueron mejores que las mantenidas por éstos con sus colonizadores franceses. Sobre todo en el ámbito rural y en las ciudades de la Oranie, donde la presencia hispana resultaba dominante. Esa realidad, no exenta de riesgos, era contemplada con recelo por la administración colonial, por los colonos de origen metropolitano, e incluso por el clero español. Todavía en 1888 cierto sacerdote peninsular residente en Orán, lamentaría que algunas españolas contrajeran matrimonio con argelinos y se hicieran musulmanas, "cosa que nos denigra ante los demás europeos» (4).

Respecto al caso que nos ocupa, mediado el mes de octubre de 1854 los cabileños de la tribu de Bordjía, comarca de Mostaganem, en la Argelia occidental, sector a la sazón definitivamente ocupado por los franceses, pero todavía sujeto a exclusivo control castrense por ser estimada como zona insegura, se presentaron al oficial responsable del Bureau Arabe de la localidad para hacerle entrega de un muchacho español, de entre trece y quince años, acogido desde hacía tiempo a la hospitalidad de la tribu. Se hallaba tan enteramente integrado en la sociedad autóctona que su aspecto $y$ atuendo parecía argelino, dominaba bien la lengua árabe y «había consentido renegar [de] su religión para hacerse musulmán” (5).

El xej del aduar había optado sin embargo por entregarle para declinar toda responsabilidad y soslayarse con los suyos a posibles represalias francesas (6). Dijo llamarse el joven José García, y ser oriundo de Málaga, "huérfano de padre y madre que, abandonado y mal pagado de los varios amos a que ha servido, se había visto en la necesidad de pedir hospitalidad a los árabes para poder subsistirn. Entre sus antiguos patronos no resultaba el mejor cierto colono español de la región del Sig, con quien se había contratado como pastor, hasta que decidió abandonarle en vista de que aquel no le retribuía su trabajo (7).

Interrogado el muchacho por las autoridades coloniales, se siguieron diferentes rectificaciones y ampliaciones del informe precedente. Declaró no recordar cuánto tiempo había transcurrido desde su llegada de España en busca de su padre, revendedor de oficio, si bien debía ser bastante, unos diez años aproximadamente. No sabía a ciencia cierta si su progenitor se apellidaba García o Jiménez, ni si vivía o no. Refirió haber fallecido su madre y, en cuanto a su padrè, dijo haberle abandonado dos veces uporque vivía con una mujer

(4) Ibídem, p. 392

(5) A. M. A. E., Correspondencia (Argel), leg. 1.818: Oficio - 15 octubre 1854-del vicecónsul de España en Mostaganem a su colega en Orán.

(6) Para una correcta comprensión de la administración militar francesa en Argelia durante la fase orleanista y en el II Imperio, en sus relaciones con la población argelina, son fundamentales los numerosos estudios de Xavier YACONO. En particular: La colonisation des plaines du Chélif 'De Lavigèrie au confluent de la Minal. Alger. 1955-1956, 2 vols. Vid. también Ch. A. JULIEN, Histoire d'Algérie Contemporaine: la conquête et les debuts de la Colonisation: 1827-1871). París. 1964.

(7) A. M. A. E., Correspondencia (Argel), leg. 1.818: Oficio - 15 octubre- del jefe del Bureau Arabe de Mostagariem al vicecónsul en Orán. 
con quien no era casado», y que escapó de casa por segunda vez hacía como año y medio.

El joven malagueño, presentado como «muy despabilado para su edad, vestido de beduino, [y] que habla perfectamente el árabe y el francés" (8), quedó bajo la custodia del comandante de Mostaganem, en tanto se procedía a la localización de posibles parientes.

El vicecónsul en Orán no tardó en tomar cartas en el asunto. De las indagaciones practicadas por él mismo se siguió que uel citado muchacho se llama José Giménez García, hijo de Antonio, natural de Málaga, residente en la plaza, antes revendedor de aceite y en la actualidad de cigarros, y de Juana García, que falleció en la indicada ciudad de Málaga en 28 de Mayo de 1854" (9). Jiménez presentaba a su vástago como mozo difícil y rebelde, que había abandonado el hogar en varias ocasiones $v$, últimamente, «fugándose de su casa para no verse obligado a seguir un oficio que le evitase la vagancia y las malas compañías». En suma, reclamaba a su hijo "para darle los consejos que debe, y obligándole a que tome oficio...».

Como quiera que en su entrevista con el vicecónsul el cigarrero se expresó "con el acento de un padre afligido" (10), y además tenía la ley de su parte, el muchacho le fue entregado. Sin duda no sin vivo disgusto del interesado, que hubiera preferido verse libre de la tutela paternal - acaso no enteramente desinteresada - y proseguir su existencia independiente y aventurera.

Sea como fuere, el cónsul en Argel aprobó la conducta de sus dos subordinados en Orán y Mostaganem, se felicitó por la diligencia y eficacia de ambos funcionarios, y se apresuró a notificar al Ministro de Estado (11) un suceso problemático, a su juicio felizmente resuelto.

\footnotetext{
(8) Ibídem, Oficio - 15 octubre 1854- del vicecónsul en Mostaganem al de Orán.

(9) Ibídem: Oficio -21 octubre 1854-- del vicecónsul de España en Orán a su colega de Mostaganem.

(10) Ibidem: Oficio - 21 octubre 1854- del vicecónsul en Orán al cónsul general en Argel.

(11) Ibídem: Despacho - 27 octubre 1854- del cónsul general de España en Argel al ministro de Estado.
} 


\section{Apéndice documental}

1. - Los cabileños de la región de Mostaganem entregan a las autoridades francesas un muchacho español, refugiado entre ellos y convertido al islamismo (octubre, 1854) (1).

Vice-Consulado de España en Mostaganem.

Señor Vice-Consul:

El Gefe del Bureau Arabe de esta localidad acaba de informarme que los árabes de la tribu de los Bordjía han conducido un muchacho español de unos quince años que se había presentado en dicha tribu pidiendo hospitalidad y había consentido en renegar [de] su religión para hacerse musulmán.

Adjunto le remito copia del despacho que dicho Gefe me ha pasado del que resulta que este muchacho se llamaría José García, natural de Málaga, huérfano de padre y madre que, abandonado y mal pagado de los varios amos que ha servido, se había visto en la necesidad de pedir hospitalidad a los árabes para poder subsistir.

Las indicaciones que preceden han sido modificadas en un interrogatorio que ha tenido lugar de orden del General Comandante de la Sub-División, ante mí y el Gefe del Bureau Arabe, en donde ha declarado que no puede precisar el tiempo que hace que vino de Málaga a Orán para juntarse con su padre que hace de revendedor. Que no sabe si es Antonio García o Antonio Ximénez como se llama su padre, porque no se acuerda si el apellido García le viene de su padre o de su madre. Que ésta murió en Málaga. Que ha abandonado dos veces a su padre, porque vivía con una muger con quien no era casado. Que hace cerca de año y medio que se fue la última vez, y que él piensa no tener más de trece años.

En vista de estas declaraciones, y persando que probablemente tiene parientes que le recogerán, hemos convenido con el consentimiento del General que yo participaré a $V$. lo que pasa, rogándole al mismo tiempo se sirva ver si puede descubrir su familia y decirme lo que debemos hacer de él.

Este muchacho, muy despabilado para su edad, vestido de beduíno, que habla perfectamente el árabe y el francés, queda bajo la guardia del Bureau Arabe hasta recibir la contestación de $V$.

Dios... etc. Mostaganem 15 octubre 1854. El Agente Consular en Comisión M. Monio.

Sr. Vice-Consul de España en Orán.

(1) Correspondencia (Argel), leg. 1.818: Oficio - 15 actubre 1854-del vicecónsul de España en Mostaganem al vicecónsul en Orán. 
II. - El comandante francés del Bureau Arabe de la subdivisión militar de Mostaganem, informa al viceconsul español en la localidad loctubre, 1854) (2).

Algérie

Division d'Oran. S. Division de Mostaganem.

Cercle de Mostaganem. Affaires Arabes.

Mostaganem, le 15 Obre. 1854

Monsieur:

Un jeune Espagnol ayant une 15ne d'années, a été amené, il y a deux jours, par des arabes de la tribu des Bordjía, chez lesquels il était allé en vagabond, chercher un asile et demander I'hospitalité; déjà il avait consenti à embrasser la religion musulmane et à s'identifier avec les indigènes; ceux-ci l'ont acueilli avec bienveillance et ne demandaient pas mieux que de conserver auprés d'eux ce jeune néophyte, mais pour ne pas se compromettre ils ont dû nous l'amener. Interrogé sur sa famille cet enfant a pretendu se nommer Joseph García, il est originaire de Málaga, il est venu en Afrique il y a une dixaine d'années, avec son père qui est mort depuis, sa mère nous dit il n'existe plus.

Avant d'aller chercher asile chez les arabes, cet enfant était berger cher un colon Espagnol du Sig qui ne lui a même payé ses services quand il est parti, avant cela il était au Caravanserail des Benichongran. Les mauvais procedés de ses maîtres jusqu'alors, et l'espoir d'une position meilleure l'avaient engagé à prendre la determination dont je viens de vous parler.

Avant de laisser ce jeune espagnol libre de sa volonté, nous avons dû vous en référer, peut-être contrairement à ce qu'il dit, a-t-il une famille à laquelle il doit être rendu.

Veuillez agréer, Monsieur le Consul, l'assurance de mon profond respect.

Pr. Le Lientenant chef du Bureau Arabe. L'officier adjoint.

[Signature Illisible.]

Monsieur le V. Consul d'Espagne à Mostaganem.

III. - El Viceconsul español en Orán averigua la identidad del muchacho (octubre, 1854) (3).

Vice-Consulado de España en Orán.

(2) Ibidem: Oficio - 15 octubre 1854- del jefe del Bureau Arabe de Mostaganem al vicecónsul españo en la plaza.

(3) Ibídem: Oficio - 21 octubre 1854- del vicecónsul de España en Orán a su colega en Mostaganem. 
En vista de la comunicación de $V$. fecha 15 del actual relativo al muchacho español de Málaga, que según sus indicaciones se llamaría José García, he practicado cuantas diligencias he creído convenientes para averiguar si dicho individuo tenía o no familia en esta.

En efecto ha resultado que el citado muchacho se llama José Giménez y García, hijo de Antonio, natural de Málaga, residente en esta plaza, antes revendedor de aceyte y en la actualidad de cigarros, y de Juana García, que falleció en la indicada ciudad de Málaga en 28 de mayo de 1854. Que, según la manifestación que me ha hecho el referido Antonio Giménez, padre del mismo muchacho, éste no ha sido una vez sola que se ha sustraído a la obediencia paterna, fugándose de su casa para no verse obligado a seguir un oficio que le evitase la vagancia y malas compañías. Que sus deseos como buen padre, y sus deberes de tal así lo exigen, son los de que con la brevedad que sea posible y sus atenciones le permitan, se recoja a dicho su hijo y se le entregue para darle los consejos que debe, y obligándole a que tome un oficio y ocupación, suplicándome con este motivo gestione cuanto esté de mi parte para que se realice el fin mencionado. En cuya virtud, y creyendo muy justa la petición del Antonio Giménez, me dirijo a $V$. a fin de que reclamando del Bureau Arabe al muchacho Antonio Giménez y García, bajo cuya guarda quedó según su referida comunicación, se sirva remitirlo a este Vice-Consulado, con el objeto de que, haciendo en tal caso comparecer a su padre, se encargue de él como corresponde y adopte sobre su cuidado y educación las medidas que le parezcan oportunas.

Dios... etc. Orán 21 de Octubre de 1854. J. Rey

Sr. Vice-Consul de España. Mostaganem.

\section{IV. - El vicecónsul en Orán notifica el suceso a su superior en Argel (octu- bre, 1854) (4).}

Vice-Consulado de España en Orán.

El Vice-Cónsul de España en Mostaganem con fecha 15 del actual y bajo el número 10, me ha dirigido la comunicación de que es copia el adjunto documento número 1, acompañándome al propio tiempo la que le fue dirigida por el Gefe del Bureau Arabe de aquella Sub-División, de que es copia el documento n. ${ }^{\circ} 2$.

Por su contenido entenderá V. S. que un joven español que decía llamarse José García, se había presentado en la tribu de Bordjía pidiendo hospitalidad y que, habiendo consentido ya abrazar la religión del Profeta, lo había presentado en dicho Bureau para declinar toda responsabilidad.

(4) líidem: Oficio - 21 octubre 1854 - del vicecónsul de España en Orán al cónsul general en Argel. 
En su consecuencia, y en vista de cuanto va referido, el expresado ViceConsul de acuerdo con el Comandante General de aquella Sub-División, había resuelto dirigirse a mí para que me informara si tenía parientes en ésta, que lo recogieran antes de dejarlo libre de su voluntad.

Sin embargo de las dificultades que se presentan en este país para descubrir el paradero de una persona, no he omitido medio alguno para averiguar el del padre de este muchacho, el cual habiendo sido encontrado e invitado a presentarse a este Vice-Consulado, lo ha verificado inmediatamente. A cuyo efecto, y después de darle conocimiento del asunto de que se trata, me ha suplicado con el acento de un padre afligido, hiciera cuanto dependiera de mí para que su indicado hijo fuera restituido en la morada paterna. Con este fin he creído deber dirigir al expresado Vice-Consul la comunicación de que es copia el documento n. ${ }^{\circ} 3$, esperando aprobará cuanto he practicado en esta circunstancia.

Dios... etc. Orán 21 Octubre 1854. Juan Rey.

Sr. Cónsul General de España en Argel.

V.-El asunto trasciende a Madrid (octubre, 1854) (5).

Consulado General de España en Argel.

Excmo. Señor:

Muy Señor mío: Por los cuatro documentos que tengo la honra de dirigir a $V$. E. adjuntos, entenderá $V$. E. de la presentación hecha por los árabes de la tribu de Bordjía al Gefe del Bureau Arabe de Mostaganem de un joven español, de edad de unos quince años, vestido de beduíno, hablando el árabe y el francés con toda perfección, que decía llamarse José García. Este joven se había presentado en la tribu pidiendo hospitalidad, y habiendo consentido después de algún tiempo en abrazar la religión musulmana, le habían presentado a dicho Gefe del Bureau Arabe para declinar toda responsabilidad ulterior.

En el momento de haber sido presentado por los árabes, este joven declaró llamarse José García; ser natural de Málaga; haber llegado a Orán hacía diez años en compañía de su padre, viudo, el cual había fallecido después. Pero dudando el Gefe aquel de la veracidad de estas declaraciones, se dirigió al Vice-Consul de aquel punto, dándole parte de la presentación de este joven y para que viera, si antes de dejarle libre, no convendría averiguar si tenía familia a la que debería entregársele.

Al recibo de esta comunicación, el Vice-cónsul se presentó en el Bureau Arabe. Habiendo sido interrogado de nuevo el joven ante el Gefe del Bureau $y$ el Vice-cónsul, las declaraciones primeras fueron modificadas de un modo

(5) Despacho - 27 octubre 1854- del consul general de España en Argel al ministro de Estado. 
que parecía acercarse más a la verdad. En su vista se determinó de acuerdo con el Comandante General de la Sub-División el que el Vice-cónsul de Mostaganem participase al de Orán lo que ocurría a fin de que hiciese por averiguar si tenía padre o familia a quien pudiese hacerse entrega.

En vista de todas estas comunicaciones, el Vice-Cónsul de S. M. en Orán practicó cuantas diligencias creyó convenientes, de cuyas resultas averiguó llamarse el joven José Giménez y García, hijo de Antonio, residente en Orán, y de Juana García, difunta. El padre del Joven declaró no ser esta la vez primra que su hijo se había sustraído de la obediencia paterna por no sujetarse a aprender un oficio que le evitase la vagancia y malas compañías. Le manifestó vivos deseos de que se le entregase con la mayor brevedad posible para darle consejos convenientes y obligarle a aprender un oficio.

En su consecuencia, el Vice-Cónsul de Orán ha contestado al de Mostaganem encargándole reclamase al muchacho y le remitiese al Vice-Consulado de Orán para que haciéndolo comparecer a su padre se le hiciese entrega formal de su hijo.

Yo no he podido menos que aprobar la conducta observada en esta circunstancia por ambos Vice-Cónsules, y me apresuro a ponerlo en conocimiento de $V$. E. para los fines convenientes.

Dios... etc. Argel 27 de Octubre de 1854. Vicente de Zugasti.

Excmo. Señor Primer Secretario de Estado y del Despacho. Madrid. 